\title{
The impact of non-native rainbow trout within Afro-montane streams in eastern Zimbabwe
}

\author{
Wilbert T. Kadye $\cdot$ Albert Chakona $\cdot$ \\ Lightone T. Marufu • Tendai Samukange
}

Received: 26 January 2013/Revised: 2 July 2013/Accepted: 20 July 2013/Published online: 3 August 2013

(C) The Author(s) 2013. This article is published with open access at Springerlink.com

\begin{abstract}
Non-native trout species have been associated with many negative effects in receiving ecosystems. The first aim of this study was to determine the impact of non-native rainbow trout Oncorhynchus mykiss on distribution and abundance of native mountain catfish Amphilius uranoscopus within Afro-montane streams in Nyanga Mountains, eastern Zimbabwe. The second aim was to compare macroinvertebrate community responses to the presence of the trout and the catfish. We examined trout impact on catfish's habitat associations, whereas macro-invertebrate composition was compared using open fish and fish exclosure experiments in habitats with and without trout. Trout influenced both the distribution and abundance of the catfish that occupied shallow reaches possibly to avoid predation from trout that occurred in the deeper habitats. Within trout invaded
\end{abstract}

Handling editor: David Dudgeon

W. T. Kadye $(\varangle)$

Department of Ichthyology and Fisheries Science, Rhodes University, PO Box 94, Grahamstown 6140, South Africa e-mail: kadyew@yahoo.com

\section{A. Chakona}

South African Institute for Aquatic Biodiversity,

Private Bag 1015, Grahamstown 6140, South Africa

L. T. Marufu - T. Samukange

Department of Biological Sciences, University of Zimbabwe, PO Box MP 167, Mt. Pleasant, Harare, Zimbabwe reaches, most macro-invertebrate taxa were more abundant in exclosure than open treatments. By contrast, within trout-free reaches, most macro-invertebrates either did not differ between treatments or were generally more abundant in open than exclosure treatments. This suggests that the macro-invertebrate communities responded differently within invaded and non-invaded reaches. By influencing distribution and abundance of native biota, non-native rainbow trout may have wider ecological effects, such as influencing trophic interrelationships within invaded habitats.

Keywords Invasions - Rainbow trout · Amphilius uranoscopus · Macro-invertebrates · Physical habitat

\section{Introduction}

Invasion by non-native species is now recognised as one of the major drivers of biodiversity loss globally (Pimentel, 2011). Freshwater fishes are among the most widely introduced vertebrate group worldwide, and represent the one of the best-studied indicators of invasion impacts (Rahel, 2002; Leprieur et al., 2008; Strayer, 2010). Non-native fishes have disrupted the biota of their recipient ecosystems directly through predation and competition, and indirectly by altering the behaviour and abundance of prey, and disturbing food-web interrelationships (Flecker \& Townsend, 
1994; Nyström \& McIntosh, 2003; Baxter et al., 2004). The general theory of invasion disturbances posits that impacts are often a consequence of cumulative effects related to the distribution range of invaders, their relative abundances within that range, and their per capita effects on individuals, populations and communities of native species (Parker et al., 1999; Dunham et al., 2002; Young et al., 2010; Kadye \& Booth, 2012). Assessing the role of invaders and their associated impacts within freshwater habitats is therefore essential in understanding the ecological role of non-native species in their recipient ecosystems.

Non-native trout species, especially of the genera Oncorhynchus and Salmo, are among the most globally widespread within freshwater ecosystems (Welcomme, 1988; Cambray, 2003; Crawford \& Muir, 2008). Non-native trout species have become established within both previously fishless habitats as new functional groups and within habitats that already contain fish (Simon \& Townsend, 2003; Strauss et al., 2006; Strayer, 2010). Their impacts on native fauna have been observed to range from subtle, such as influencing behaviour, distribution patterns and habitat use (Simon \& Townsend, 2003; Penaluna et al., 2009), to local extirpation of local species (McIntosh, 2000; Bosch et al., 2006; Kadye \& Magadza, 2008) and broad ecosystem impacts such as trophic cascades (Townsend \& Crowl, 1991; Biggs et al., 2000; Nyström et al., 2001). In southern Africa, trout species have predominantly been introduced into the cool upper reaches of rivers (Cambray, 2003). There are serious ecological and conservation concerns in this region because many of the upland tributaries are important refugia for the remnant populations of endemic and range-restricted native ichthyofauna, such as mountain catfishes and other endemic cyprinid barbs (Swartz et al., 2004; Tweddle et al., 2009; van Oosterhout et al., 2009). The risk of trout invasions, primarily through angler introductions, is high in many southern African rivers, but their impacts are less understood, and have rarely been assessed especially in tropical southern Africa (Kadye \& Magadza, 2008).

Two mountain catfishes, Amphilius uranoscopus and A. natalensis, occur in the upper reaches of streams in the Nyanga Mountains in eastern Zimbabwe (Bell-Cross \& Minshull, 1988; Marshall, 2011). A. uranoscopus is the most common and widespread of the two mountain catfishes (Marshall, 2011). The region also harbours a number of unique macroinvertebrate taxa, although most of them are yet to be described to species (Chakona et al., 2008). Rainbow trout Oncorynchus mykiss and brown trout Salmo trutta were first introduced into these streams in the early 1900s (Toots, 1970) and were supplemented over the years by hatchery-reared fish (TurnbullKemp, 1957; MacGown, 1970). The stocking of these fishes is now much less frequent and brown trout have disappeared from most streams, but rainbow trout is still common, although their numbers may have declined in some of the streams (Marshall, 2011). Non-native rainbow trout has been observed to prey on both the mountain catfish and macro-invertebrates within many streams in Nyanga Mountains (Butler \& Marshall, 1996). Some studies elsewhere have noted that although the mountain catfish is a widespread species, local extirpations are likely where its preferred habitat overlaps with that of rainbow trout (Kadye \& Magadza, 2008; van Oosterhout et al., 2009). Furthermore, within trout invaded streams, direct predation and indirect influence on the behaviour have been observed to influence both distribution and abundance of benthic macro-invertebrates communities (Simon \& Townsend, 2003; Meissner \& Moutka, 2006). Therefore, examining the fish species and habitat inter-relationships is important in determining whether specific habitats act as refugia within invaded streams (van Oosterhout et al., 2009). In addition, since macro-invertebrates are an integral component of headwater streams, it is important to examine their community dynamics in relation to the presence of non-native rainbow trout.

In this study, we first examined the impact of rainbow trout on the distribution and abundance of the mountain catfish by assessing whether trout influenced the catfish's habitat associations. Second, we compared benthic macro-invertebrate composition within invaded and non-invaded localities using short-term fish-exclosures and open-fish experiments. We hypothesized that the native mountain catfish would utilise a wide range of habitats in trout-free reaches, but would select habitats that minimise predation risk in reaches with trout. We also hypothesized that the non-native rainbow trout would cause detectable changes in macro-invertebrate composition as some taxa would be susceptible to predation, whereas the native mountain catfish would have subtle effects on 
macro-invertebrate composition because it has coevolved with its potential prey.

\section{Materials and methods}

Study area

The Nyanga Mountains lie in the northern part of the mountain range that forms the border between Zimbabwe and Mozambique (Fig. 1). The greater part of the plateau lies at altitudes above $1,800 \mathrm{~m}$, rising to 2,593 $\mathrm{m}$ on Mount Nyangani, the highest point in Zimbabwe. Most of the area is located within the Nyanga National Park, and consists of soils derived from granite and dolerite, and covered by Afromontane grassland and forest patches. Air temperatures are relatively low, with a maximum of $25^{\circ} \mathrm{C}$ and mean annual temperatures between 15 and $18^{\circ} \mathrm{C}$. The annual rainfall is around $1,700 \mathrm{~mm}$, falling mostly between October-April. Frost is common during the months of May to August. Streams and rivers in the park are perennial, flowing west and north-west into the Zambezi system, through the Nyangombe and Kairezi Rivers, and east through the Pungwe River system. The mountain catfish occurs in all major streams and their tributaries within the national park. Other fish species that occur within the region include the Natal mountain catfish A. natalensis and the mottled eel Anguilla bengalensis, but these were not collected during this study. Rainbow trout was introduced into the headwaters of all major streams and occurs at altitude greater than 1,800 $\mathrm{m}$ where temperature is generally low. Within Mare River, a major tributary of Nyamombe, the rainbow trout occurs within impoundments but has not established in the headwater sections of the river. Sampling for this study was restricted to first order headwater streams.

Fish sampling and habitat assessment

Fish sampling was conducted in April, June and September 2009. Samples were collected at seven sites from four headwater streams located at altitudes greater than $1,800 \mathrm{~m}$ (Fig. 1). The scarcity of troutfree streams precluded a multiple trout-free and troutinvaded experimental design, and constrained the study design to one trout-free and three trout-invaded streams. In order to offset the potential for confounded comparisons resulting from the limited real replication of this design, we selected sites that had similar riparian vegetation that was dominated by Afromontane grasslands and had similar physicochemical parameters (Bere et al. 2013). This was to insure that study sites were similar and no variables other than trout presence differed among them. Three sites were selected in Nyamombe River system; one in the headwaters of the main-stem above a waterfall where rainbow trout was present, and two in the headwaters of Mare River where rainbow trout was absent. Four other sites were in two headwater streams of the Pungwe River system where rainbow trout was present.

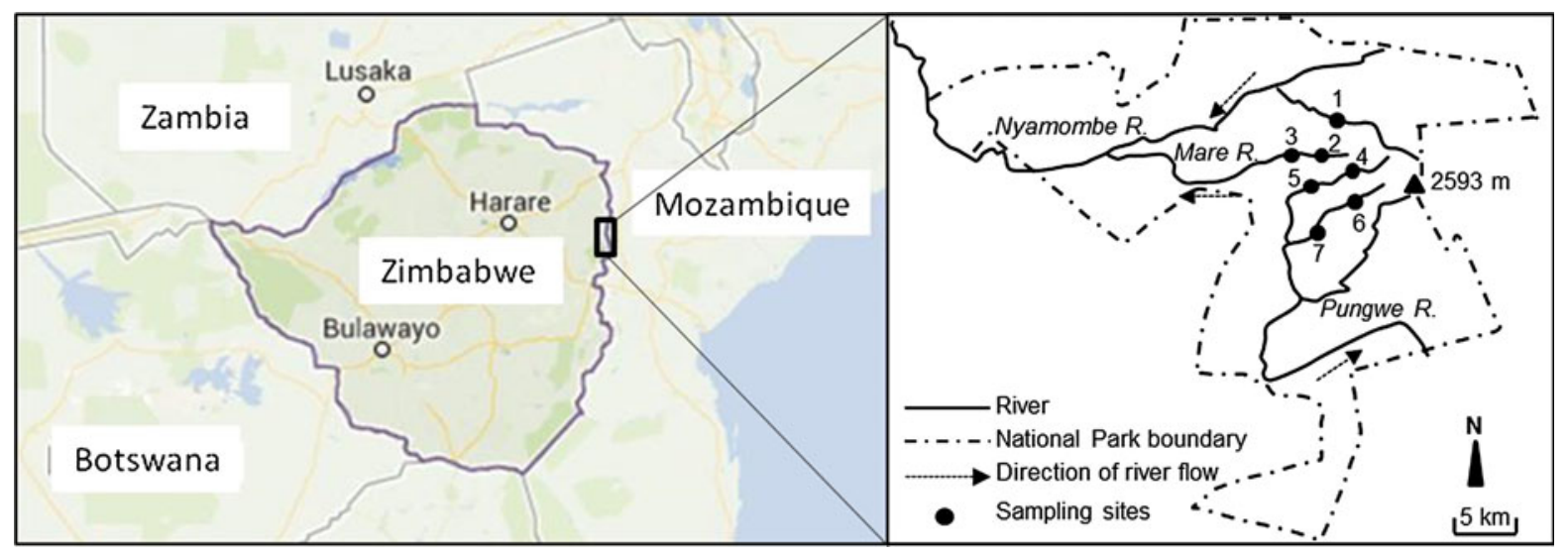

Fig. 1 The study area showing the sampling sites and rivers within Nyanga National Park, eastern Zimbabwe. The macro-invertebrate experiments were conducted in streams without the rainbow trout (sites 2,3) and with the rainbow trout $($ sites 4,5$)$ 
Each sampling site was divided into three reaches, about 30-50-m long, each of which was then blocked with a fine meshed net at either end before sampling. The sampling reaches within each site were approximately $100 \mathrm{~m}$ apart. This constituted 21 sampling reaches in total. The total length of the sampled reach was measured, and ten transects were set perpendicular to the direction of flow to measure physical habitat variables within each reach. The measurements made were depth and substrate types at three points along each transect and width for each transect. At each point, substrate composition was visually assessed within a radius of $30 \mathrm{~cm}$. There were therefore 30 points assessed for depth and substrate composition at each reach. Each substrate category was expressed as a proportion (\%) based on these points for each reach (Table 1). The substrate types were categorised following Gorman \& Karr (1978) and Schlosser (1982) as silt $(<0.05 \mathrm{~cm})$, sand $(0.05-2 \mathrm{~cm})$, gravel $(2-10 \mathrm{~cm})$, pebble $(10-30 \mathrm{~cm})$, and boulder $(30-50 \mathrm{~cm})$. Velocity was measured at the centre of each transect using an FP201 current meter (Global Water Inc., CA, USA). The sampled reaches ranged from 0.7 to $1.9 \mathrm{~m}$ and 30 to $50 \mathrm{~m}$ in width and length, respectively (Table 1). Fish were captured by a single pass with a Deka 3000 Backpack electric fisher powered by a $12 \mathrm{~V}$ battery. Captured fish were identified to species and measured for standard length (SL).

\section{Macro-invertebrate experiment}

To compare macro-invertebrate responses to presence of native and non-native fish, we conducted an experiment in two headwater streams; one without the rainbow trout (sites 2,3) and another with the rainbow trout (sites 4, 5) (Fig. 1). The lack of multiple trout-free streams was compensated by using cage experiments that were replicated within streams that had comparable environmental conditions. We considered this as the most rigorous approach available to offset the potential for the responses to be confounded by small-scale prey movements and historical effects of trout presence. In each stream, we used a completely randomised experimental design with two treatments: (1) open fish and (2) fish exclosure. Each treatment had five replicate cages. Experimental cages, each measuring $2 \times 1 \times 1 \mathrm{~m}$ in length, width and height, respectively, were constructed on steel frames. We chose these dimensions to allow easy access for sampling macro-invertebrates from an area of $1 \mathrm{~m}^{2}$ within each cage. Fish exclosures were fitted with fine gauze mesh $(3 \mathrm{~mm})$ and a $30-\mathrm{cm}$ skirt that was secured at the bottom to prevent fish from entering. Open fish cages were set as steel frames that were secured at the bottom. The cages were placed at depths of $0.2-0.5 \mathrm{~m}$ with homogenous pebble substrate that was the dominant substratum. All cages were deployed in April and sampled in June and September 2009. During sampling, pebbles were picked and washed with stream water into a sampling bucket and then filtered through a macro-invertebrate net (mesh size $250 \mu \mathrm{m}$ ). The animals were preserved in $70 \%$ ethanol. In the laboratory, the animals were sorted and identified to genus for most taxa using an Olympus (SZX10) stereomicroscope at 10× magnification. The identification followed the key of Harrison (2002) for Chironomidae, de Moore (2002) for Simuliidae, Barber-James \& Lugo-Ortiz (2003) for Ephemeroptera, de Moore and Scott (2003) for Trichoptera and Samways \& Wilmot (2003) for Odonata.

Data analysis

The rainbow trout and the mountain catfish distribution were recorded based on both the presence/absence and relative abundance. The relative abundance of fish was expressed as catch per unit effort (CPUE) as numbers caught per minute of electric fishing (Kadye $\&$ Marshall, 2007). To determine the rainbow trout impact on the mountain catfish distribution, we used a mixed logistic regression, with mountain catfish distribution (presence/absence) as a response, habitat variables as continuous variables and rainbow trout presence/absence as a class variable. Collinearity among habitat variables was initially detected using variance inflation factor (VIF) for each regression coefficient. Variables with VIF $>5$ were considered to indicate collinearity (Heiberger \& Holland, 2004) and were removed from the analysis. A forward stepwise procedure was then used to select best predictor variables. Within the stepwise procedure, variables were penalised using the Akaike's information criterion (AIC), which was defined as: $\mathrm{AIC}=-2 \ln (L)+$ $2 k$, where $L$ is the maximised likelihood function for the model and $k$ is the number of parameters in the fitted model. The logistic regression coefficients were 


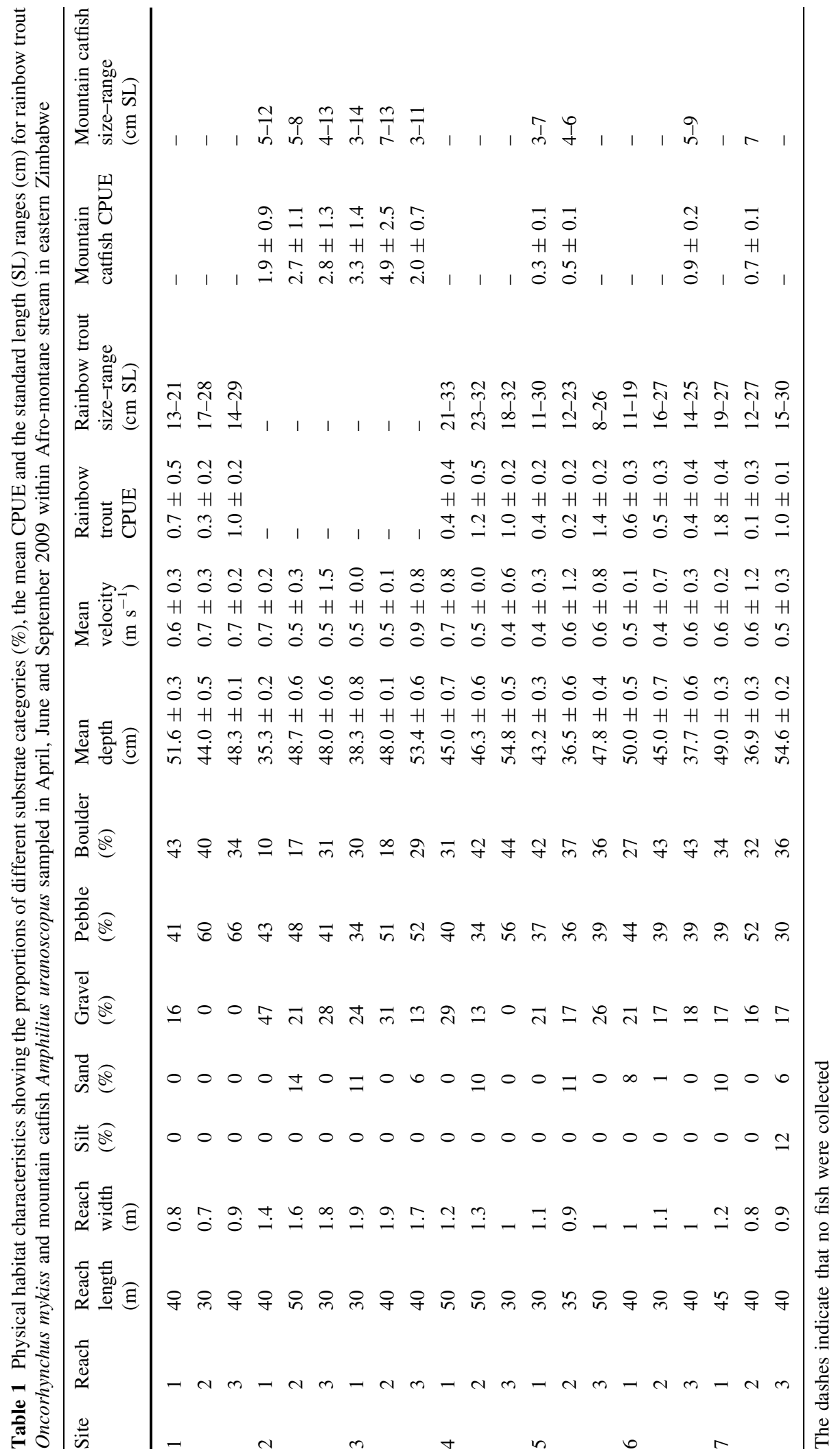


used to evaluate the change in odds ratios between the predictor variables and their response. The odds ratio is the multiplicative factor by which the odds of a response variable changes in relation to change in the predictor variable (Quinn \& Keough, 2002). $\chi^{2}$ Goodness-of-fit test, based on residual deviance, was used to test the significance of the model.

To determine trout impact on catfish abundance, we first compared catfish CPUE between localities with and without trout. We then used linear mixed-effects models to compare the relationship between the mountain catfish CPUE and habitat in localities with and without the rainbow trout. The fixed effects were the habitat variables and the random-effects were sites $(S)$ and reaches nested within sites $(S(R))$. The models were of the form: $y_{i}=X_{i} \beta+Z_{i} b_{i}+\varepsilon_{i}$, where $X_{i}$ was the $n_{i} \times p$ matrix of the fixed-effects (habitat variables), $\beta$ was the $p \times 1$ vector of fixed-effects coefficients, $Z_{i}$ was the $n_{i} \times q$ matrix of the random effects $(S(R))$, $b_{i} \sim N\left(0, \sigma^{2}\right)$ was the $q \times 1$ vector of random-effects coefficients, $\varepsilon_{i} \sim N\left(0, \sigma^{2}\right)$ was the residual error. This was tested under the null hypothesis of independence (i.e., no relationship) between the mountain catfish CPUE and predictor variables both for sites with or without trout. All environmental variables transformed into $z$ scores prior to the analyses.

Macro-invertebrate abundance data for individual taxa were $\ln (x+1)$-transformed to satisfy the requirements of normally distributed residuals and homoscedasticity. Shapiro-Wilks' test was used to test for normality. We first used linear discriminant analysis (LDA) with a stepwise procedure to discern the differences in macro-invertebrate composition between the two streams and their treatments. For each of the streams, multivariate analysis of variance (MANOVA) and single factor ANOVA were then used to compare the treatments $(T)$ and sampling periods nested within treatments $(T(P))$. All analyses were conducted in $R$ (R Development Core Team, 2012). The following libraries were used: stats for logistic regression, nlme for linear mixed-effect models and MASS for MANOVA and LDA analyses.

\section{Results}

The sampled reaches tended to be shallow with a mean depth range of $35-55 \mathrm{~cm}$, and a mean flow range of
0.4-0.9 $\mathrm{m} \mathrm{s}^{-1}$ (Table 1). Pebbles, boulders, and gravel were the most common substrate types within all reaches. The rainbow trout was the most widespread species, occurring in 15 of the 21 reaches. In comparison, the mountain catfish was collected in 10 of the 21 sampled reaches. The logistic regression model showed that the mountain catfish distribution was significantly negatively (likelihood-ratio test, $P<0.001)$ associated with the presence of rainbow trout and depth. Model comparisons showed that the trout model was significantly better than the model without trout. Regression models for these variables indicated that the odds ratios for mountain catfish distribution decreased by 6.4 in the presence of rainbow trout, whereas increasing depth decreased the odds ratios for mountain catfish distribution by 2.4 . $\chi^{2}$ Goodness-of-fit test for the mixed logistic regression was not statistically significant $\left(\chi_{60}^{2}, P>0.05\right)$, indicating adequate fit of the model to the data.

The mountain catfish was significantly abundant ( $t=6.42, P<0.01)$ in reaches without rainbow trout (mean CPUE $=2.42 \pm 1.7$ fish per minute) compared to those that had trout (mean CPUE $=0.10 \pm 2.5$ fish per minute). In reaches with rainbow trout, comparisons of the fish and habitat relationship based on the linear mixed-effects model showed a significant $\left(F_{1,20}=5.5, P<0.05\right)$ negative relationship between the mountain catfish CPUE and depth (Table 2). By contrast, within rainbow trout-free reaches, the mountain catfish CPUE was significantly $\left(F_{1,8}=5.8\right.$, $P<0.05)$ negatively related to boulder substrate and positively related to depth $\left(F_{1,8}=3.6, P=0.1\right)$.

A total of 20 macro-invertebrate taxa, representing four orders were collected from the cages (Table 3 ). In general, large-bodied Odonate taxa Atoconeura sp. and Aeshna sp. were more abundant in Mare River that had no trout compared to Pungwe River that had trout. By contrast, small bodied macro-invertebrates, such as Baetis spp., Chironominae and Simulium sp. were more abundant within Pungwe River compared to Mare River. Linear discriminant analysis (LDA) showed significant differences between rivers and their treatments (Wilks' $\lambda=0.10, \quad F_{9,30}=31.9$, $P<0.01)$. The ordination biplot showed the separation of the rivers on the first discriminant axis (LDA 1) with the treatments being separated on the second discriminant axis (LDA 2) (Fig. 2). Comparisons of macro-invertebrate composition between treatments 
Table 2 Linear mixed-effects models coefficients for the relationship between mountain catfish Amphilius uranoscopus CPUE and habitat variables in reaches with $\left(R^{2}=53.7 \%\right)$ and without $\left(R^{2}=45.9 \%\right)$ rainbow trout Oncorhynchus mykiss sampled within Afro-montane stream in eastern Zimbabwe

\begin{tabular}{|c|c|c|c|c|c|c|c|c|c|c|}
\hline & \multicolumn{5}{|c|}{ Sites with trout } & \multicolumn{5}{|c|}{ Sites without trout } \\
\hline & Estimate & SE & df & $F$ & $P$ & Estimate & SE & df & $F$ & $P$ \\
\hline Intercept & 0.15 & 0.07 & 20 & 5.10 & 0.03 & 1.73 & 0.64 & 8 & 8.98 & 0.02 \\
\hline Gravel & -0.01 & 0.03 & 20 & 0.03 & 0.66 & -0.28 & 0.30 & 8 & 0.81 & 0.40 \\
\hline Sand & 0.03 & 0.02 & 20 & 1.18 & 0.22 & -1.05 & 0.52 & 8 & 0.28 & 0.61 \\
\hline Boulder & -0.01 & 0.02 & 20 & 0.50 & 0.79 & -1.16 & 0.44 & 8 & 5.77 & 0.04 \\
\hline Depth & -0.06 & 0.03 & 20 & 5.52 & 0.03 & 0.70 & 0.37 & 8 & 3.56 & 0.10 \\
\hline Velocity & 0.00 & 0.02 & 20 & 0.01 & 0.96 & -0.01 & 0.22 & 8 & 0.01 & 0.95 \\
\hline
\end{tabular}

indicated significant differences for both the Mare River (MANOVA $F_{9,8}=9.7, P<0.01$ ) that had no trout and the Pungwe River (MANOVA $F_{5,12}=33.5$, $P<0.01)$ that had trout. Within the Mare River, most macro-invertebrates were either more abundant in the open than the exclosure, such as Pseudoponnata, Limnophila and the Trichopteran taxa Hydropsyche and Cheumatopsyche, or did not differ between treatments, such as Euthralus sp. and Afronurus sp. An exception was Baetis spp. and Caenis sp. that were more abundant in the exclosure than the open treatment (Fig. 3). In this river, the abundances of Baetis spp., Hydropsyche sp. 1, Cheumatopsyche spp. and Limnophila sp. differed significantly between treatments (ANOVA, $P<0.05$ ) (Table 4). Furthermore, Baetis spp., Hydropsyche sp. 1, Afronurus sp., Caenis sp., and Euthralus sp. abundances differed significantly (nested ANOVA, $P<0.05$ ) between sampling periods. Within Pungwe River, all macro-invertebrate taxa were generally more abundant in exclosure than open treatment (Fig. 3), with Baetis spp., Caenis sp.and Euthralus sp. exhibiting significant differences between treatments (ANOVA, $P<0.05$ ) and between sampling periods (nested ANOVA, $P<0.05$ ), whereas Cheumatopsyche spp. and Afronurus sp. only showed significant differences between sampling periods (nested ANOVA $P<0.05$ ) (Table 4).

\section{Discussion}

The hypothesis that in the absence of the rainbow trout O. mykiss, the native mountain catfish A. uranoscopus would utilise a wide range of habitats use was supported because individuals of the mountain catfish were collected from all the habitats sampled within trout-free reaches in this study. Within the rainbow trout-free stream, the mountain catfish exploited a broad range of depths $(35-54 \mathrm{~cm})$ and occurred in reaches with diverse bottom substrates although it appeared to avoid habitats with high proportion of boulders. This result was consistent with studies by Fouche et al. (2005) and van Oosterhout et al. (2009) who investigated habitat use of the mountain catfish in undisturbed mountain streams in South Africa. In undisturbed habitats, the mountain catfish is known to be ubiquitous, preferring coarse substrates that provide both refuge and foraging ground in both shallow and deep habitats. Within headwater streams, such habitats are often characterised by low temperature, high flow rate, and high dissolved oxygen (Kadye et al., 2008; van Oosterhout et al., 2009).

Measurable changes in the mountain catfish abundance and habitat use were, however, detected in reaches that contained the rainbow trout. In the presence of rainbow trout, depth was found to be the strongest predictor of both mountain catfish distribution and abundance. The results revealed high probably of catfish occurring in shallow habitats in sites with trout, whereas the detection of this species was lowest in deeper habitats when the rainbow trout was present. Similarly, the mountain catfish abundance decreased with increasing depth in the presence of trout. Thus, there was strong evidence of rainbow trout effect on both distribution and abundance of mountain catfish in the tributaries of the Nyanga Mountains. Kadye \& Magadza (2008) documented similar spatial segregation between non-native rainbow trout and mountain catfish on the Nyika Plateau in Malawi. Shifts in habitat selection and decrease in abundance of native fishes in trout-invaded streams have been reported elsewhere. For example Morita et al. 
Table 3 Mean ( \pm SD) macro-invertebrate abundance (no. $\mathrm{m}^{-2}$ ) in experimental cages sampled in June and September 2009 within a river with trout (Pungwe River) and without trout (Mare River) in eastern Zimbabwe

\begin{tabular}{|c|c|c|c|c|c|c|c|c|}
\hline \multirow[t]{3}{*}{ Order/taxa } & \multicolumn{4}{|l|}{ Mare River } & \multicolumn{4}{|c|}{ Pungwe River } \\
\hline & \multicolumn{2}{|l|}{ June } & \multicolumn{2}{|l|}{ September } & \multicolumn{2}{|l|}{ June } & \multicolumn{2}{|l|}{ September } \\
\hline & Open & Exclosure & Open & Exclosure & Open & Exclosure & Open & Exclosure \\
\hline \multicolumn{9}{|l|}{ Ephemeroptera } \\
\hline Baetis spp. & $8.0 \pm 2.4$ & $11.0 \pm 5.2$ & $28.4 \pm 7.0$ & $42.0 \pm 10.2$ & $7.0 \pm 2.3$ & $12.4 \pm 4.5$ & $30.0 \pm 13.3$ & $66.8 \pm 13.9$ \\
\hline Acanthiops sp. & $3.4 \pm 2.3$ & $4.4 \pm 3.0$ & $12.2 \pm 3.0$ & $20.8 \pm 8.2$ & - & - & $9.6 \pm 5.8$ & $16.6 \pm 9.2$ \\
\hline Pseudoponnata sp. & $3.2 \pm 1.9$ & $3.0 \pm 2.8$ & $5.6 \pm 2.1$ & $4.8 \pm 1.9$ & - & - & - & - \\
\hline Choleocleon sp. & - & - & - & $0.6 \pm 0.9$ & $3.0 \pm 3.1$ & $3.0 \pm 2.5$ & $11.2 \pm 5.6$ & $9.6 \pm 3.1$ \\
\hline Caenis sp. & $5.4 \pm 2.2$ & $3.2 \pm 1.6$ & $5.8 \pm 2.9$ & $10.0 \pm 3.5$ & - & $2.6 \pm 1.1$ & $4.8 \pm 2.4$ & $9.6 \pm 5.5$ \\
\hline Afronurus sp. & $1.8 \pm 1.3$ & $0.8 \pm 1.3$ & $9.6 \pm 4.5$ & $9.2 \pm 3.7$ & - & $3.0 \pm 2.8$ & $5.4 \pm 2.5$ & $7.0 \pm 5.4$ \\
\hline Euthralus sp. & $5.6 \pm 2.1$ & $3.8 \pm 0.8$ & $11.6 \pm 3.1$ & $11.2 \pm 4.0$ & - & $2.0 \pm 2.1$ & $3.8 \pm 3.0$ & $7.8 \pm 4.9$ \\
\hline Thalerosphurus sp. & $0.2 \pm 0.4$ & - & - & - & - & - & $0.6 \pm 1.3$ & - \\
\hline Trichorythidae & $2.8 \pm 1.3$ & $0.8 \pm 1.9$ & $1.2 \pm 1.3$ & $2.0 \pm 1.6$ & - & - & - & - \\
\hline Teloganonidae & - & - & - & - & - & $1.4 \pm 1.3$ & - & - \\
\hline \multicolumn{9}{|l|}{ Diptera } \\
\hline Chironominae & $6.8 \pm 3.6$ & $5.8 \pm 3.0$ & $8.8 \pm 2.3$ & $11.4 \pm 5.1$ & $6.0 \pm 4.2$ & $3.6 \pm 2.1$ & $17.8 \pm 6.7$ & $41.4 \pm 34.3$ \\
\hline Simulium sp. & $11.4 \pm 9.4$ & $6.6 \pm 4.1$ & $17.0 \pm 7.7$ & $22.8 \pm 9.3$ & $0.8 \pm 1.3$ & - & $43.6 \pm 26.2$ & $42.6 \pm 32.5$ \\
\hline Limnophila sp. & $1.0 \pm 1.4$ & $1.0 \pm 1.4$ & $2.8 \pm 0.8$ & $0.2 \pm 0.4$ & - & - & - & - \\
\hline \multicolumn{9}{|l|}{ Odonata } \\
\hline Atoconeura sp. & $7.6 \pm 6.9$ & $1.6 \pm 1.5$ & $11.8 \pm 4.8$ & $3.0 \pm 2.0$ & - & - & $0.8 \pm 1.1$ & - \\
\hline Aeshna sp. & $3.8 \pm 2.4$ & $3.4 \pm 4.8$ & $5.2 \pm 2.5$ & $2.8 \pm 1.8$ & - & - & $1.8 \pm 1.6$ & $0.8 \pm 0.8$ \\
\hline \multicolumn{9}{|l|}{ Trichoptera } \\
\hline Hydropsyche sp. 1 & $9.2 \pm 1.3$ & $5.4 \pm 3.8$ & $11.8 \pm 4.1$ & $5.6 \pm 2.6$ & $1.4 \pm 0.9$ & - & $7.8 \pm 3.5$ & $8.2 \pm 4.1$ \\
\hline Hydropsyche sp. 2 & $1.0 \pm 1.2$ & $0.2 \pm 0.4$ & $5.2 \pm 2.2$ & $2.4 \pm 1.5$ & - & - & - & - \\
\hline $\begin{array}{l}\text { Cheumatopsyche } \\
\text { spp. }\end{array}$ & $3.6 \pm 2.5$ & $1.4 \pm 1.3$ & $5.4 \pm 3.0$ & $2.2 \pm 1.3$ & $1.4 \pm 0.5$ & $1.2 \pm 1.1$ & $10.2 \pm 6.3$ & $10.4 \pm 7.8$ \\
\hline Macrostemum sp. & $5.8 \pm 1.5$ & $2.4 \pm 2.3$ & $12.0 \pm 6.0$ & $4.6 \pm 2.1$ & - & - & $2.0 \pm 2.8$ & $1.0 \pm 1.0$ \\
\hline Chimara sp. & $1.0 \pm 1.4$ & $1.0 \pm 1.4$ & $4.8 \pm 1.6$ & $4.0 \pm 3.5$ & - & $2.2 \pm 2.6$ & - & - \\
\hline
\end{tabular}

The dashes indicate that the macro-invertebrate taxa was absent

(2004) noted that native white-spotted charr Salvelinus leucomaenis within headwater reaches of the Hekirichi River in Japan preferred pools to riffles in the absence of non-native trout, but predominantly utilised shallow riffles in the presence of trout. Invasion by non-native trout has also been implicated as the major causal factor of the disjunct distributions of the roundhead and flathead galaxiids in New Zealand (Townsend, 1996), and Galaxias truttaceus in Australia (Ault \& White, 1994). The impact of trout species on native stream-fish densities has been reported by McDowall (2003) who found that densities of Galaxias divergens were twice as high in trout-free habitats compared to invaded habitats.

The rainbow trout could have altered mountain catfish habitat associations and abundances through direct predation, as reported from previous studies (Butler \& Marshall, 1996; Marriott et al., 1997; Kadye \& Magadza, 2008). Because deeper habitats provide refugia and optimal feeding habitats for trout (McIntosh, 2000; Morita et al., 2004; Kadye et al., 2008), particularly the larger-sized individuals (pers. obs), predation pressure on the mountain catfish is likely to be highest in the deeper pools. This could explain why the catfish retreated into shallow habitats that were likely to curtail hunting or predation success of the large-sized trout. Instances of native species cooccurring with trout have been observed to be associated with either strong predator-prey interactions (McIntosh, 2000), or within habitats containing juvenile trout that have less predatory impact (Glova 


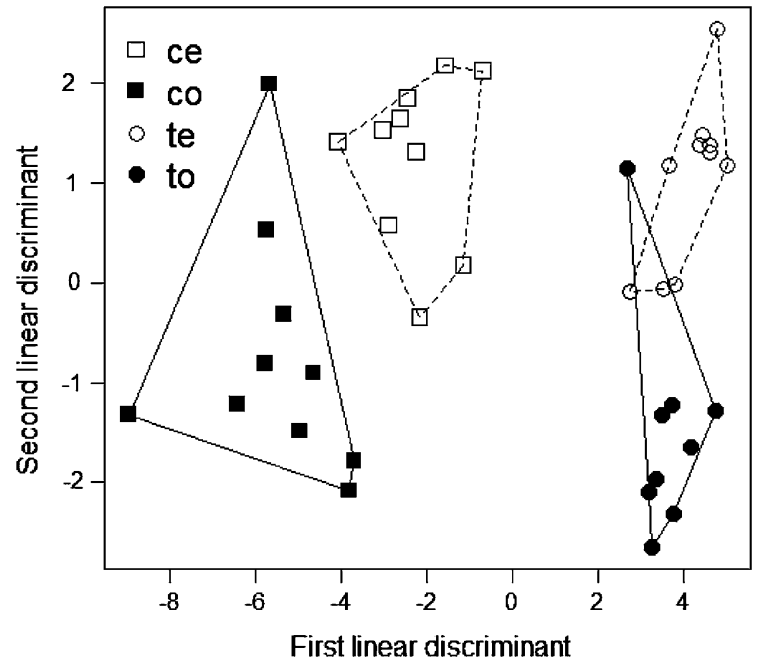

Fig. 2 Linear discriminant analysis (LDA) for macro-invertebrate composition sampled in experimental cages in rivers with trout (Pungwe River) and without trout (Mare River). The treatments were catfish exclosure (ce), catfish open (co), trout exclosure (te), and trout open (to)

et al., 1992). Predation impact by trout has also been reported to be size-dependent (Glova, 2003; Bonnett \& McIntosh, 2004). van Oosterhout et al. (2009) suggested that, due to their small size, the mountain catfish utilises the shallow riffles as daytime refugia from predation by large trout in the deeper open waters, but would possibly forage in the deeper habitats at night. This combination of behaviour (nocturnal feeding) and morphological adaptation, owing to their slender and dorsoventrally compressed body which allows maintenance of position in shallow riffle habitats with faster current velocity (van Oosterhout et al., 2009), may explain the ability of the mountain catfish to persist, albeit in low abundance, within trout-invaded streams (Kadye \& Magadza, 2008). It is likely, however, that the mountain catfish with trout-invaded reaches may occupy sub-optimal habitat, which may influence their foraging, recruiting, and reproductive success (Ngugi et al. 2009). Cases where native taxa have been forced to occupy marginal or sub-optimal habitats have been documented in other studies for native fishes (Morita et al., 2004; Kadye \& Magadza, 2008; Ngugi et al., 2009) and amphibians (Bosch et al., 2006). These marginal habitats may, however, be less optimal and could further expose the catfish to terrestrial predators such as otters and predatory birds, and therefore may not be suitable for long-term sustenance of large catfish populations. Other studies on catfishes have shown high predation pressure by terrestrial predators on large individuals at shallow depths (Power, 1984).

The hypothesis that the macro-invertebrate assemblages would show differential responses to the impacts of the two fish species considered in this study, catfish and trout, was supported. It was likely that certain macro-invertebrates had already been eliminated through predation by trout within the invaded reaches. For example, Butler \& Marshall (1996) reported trout predation on river crab Potamonautes perlatus and drifting macro-invertebrates within the study area. During this study, we found low abundance of Odonate taxa within trout-invaded compared to the uninvaded reaches. Many studies have shown that large predatory macro-invertebrates are vulnerable to trout predation (Flecker \& Townsend, 1994; Schofield et al., 1988). Since invasive predators, such as trout, are opportunistic feeders, they tend to target the most conspicuous and accessible prey that usually result in a corresponding decline in their abundance and biomass (Englund \& Polhemus, 2001; Meissner \& Moutka, 2006; Miller \& Crowl, 2006; Johnson et al., 2009). Odonates are considered to be keystone macro-invertebrate predators (Fincke et al., 1997) that regulate abundance of their prey thereby reducing dominance of certain species and maintaining diversity (Donald \& Anderson, 2003). In this study, the high abundance of some taxa such as Baetis spp., Chironominae and Simulium sp., which are considered the common prey, may suggest a response to the low abundance of macro-invertebrate predators in habitats with trout. By contrast, the low abundance of these macro-invertebrate taxa within trout-free habitats is reflective of the importance of both catfish and macroinvertebrate predators as regulators of community composition.

Comparisons of macro-invertebrate composition between experimental treatments suggest differential responses to fish in both rivers. Within trout-free zones, the macro-invertebrates were either abundant in exclosure treatment or did not differ between treatments, except for Baetis spp. and Caenis sp. that were abundant in open treatment. This suggests that most macro-invertebrates were either less responsive to the presence of the mountain catfish as a natural predator or did not recruit successfully within the exclosure treatment. Experimental cage design, such as the fine mesh and the presence of a skirt at the bottom, could 


\section{Mare River}
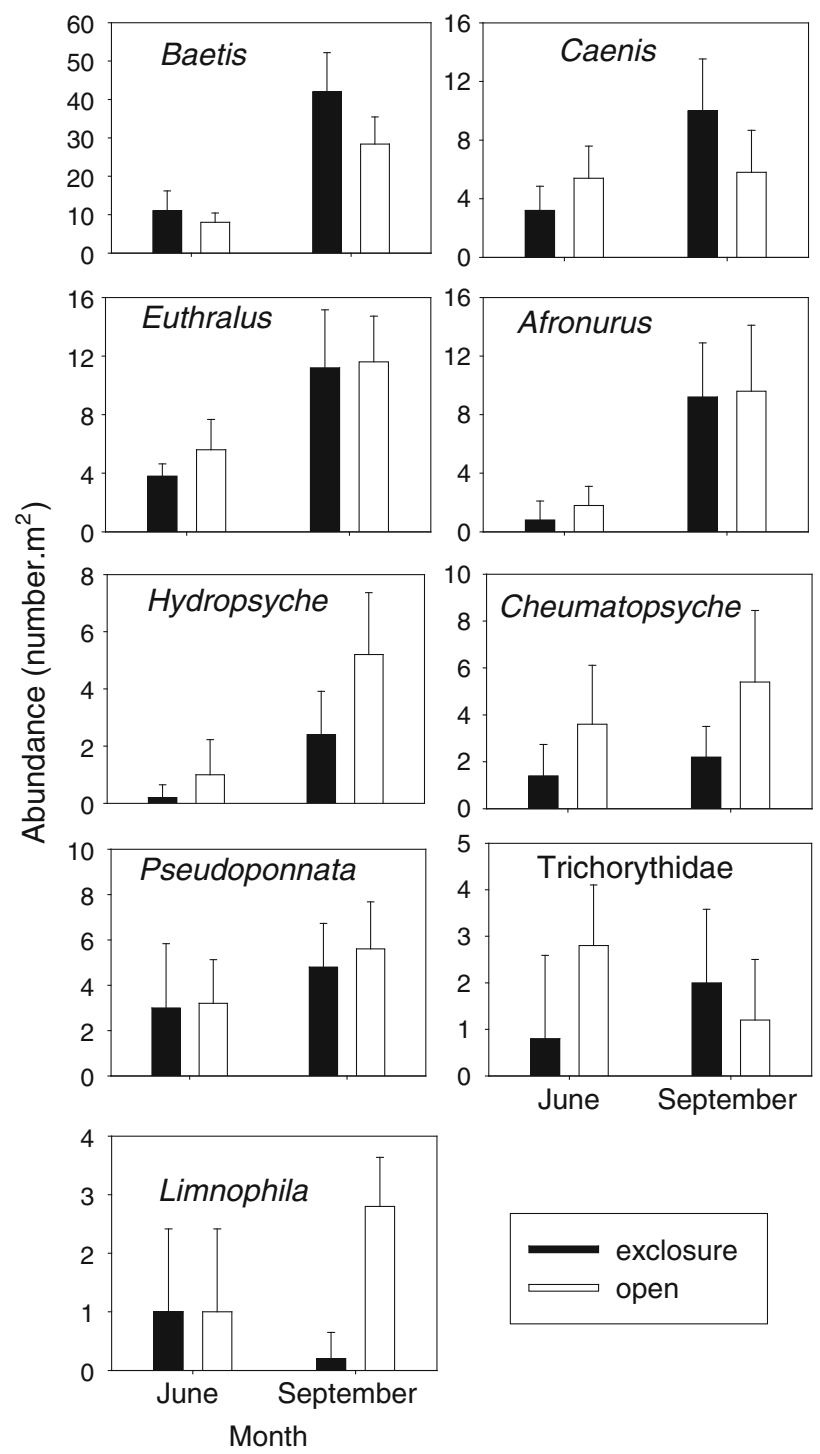

Pungwe River
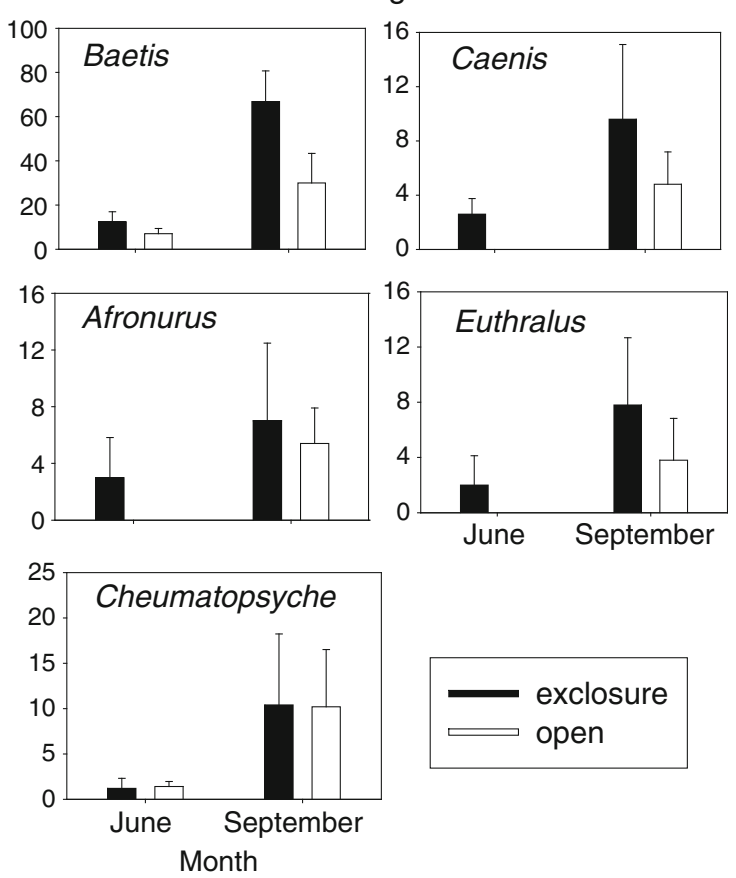

Fig. 3 Mean $( \pm \mathrm{SD})$ abundance of macro-invertebrates that was important in stepwise linear discriminant analysis. The macroinvertebrates were sampled in Mare River that had no trout and Pungwe River that had trout

also have had a confounding influence on the potential recruitment and establishment of benthically dispersing macro-invertebrates, such as trichopterans. Trichopteran caddis flies, which are considered to be the most important prey for catfish (van Oosterhout et al., 2009), were more abundant in open than exclosure treatment in Mare River. Nevertheless, taxa such as Baetis spp. and Caenis sp. that were considered the most common prey were relative abundance in the exclosure treatment. This suggests predator avoidance behaviour by these taxa, possibly from both the mountain catfish and predatory odonate taxa that were abundant in Mare River. Chakona et al. (2007) showed that the population densities of these taxa were regulated by both fish and odonate predators. By comparison, within trout-invaded Pungwe River, most macro-invertebrates were abundant in exclosure compared to open treatments. In particular, we found high abundances of Baetis spp. and Caenis sp. in exclosure compared to open treatments. This suggests a response 
Table 4 MANOVA and ANOVA results for differences in macro-invertebrate composition between treatments in experimental cages sampled within a river with (Pungwe River) and without (Mare River) rainbow trout Oncorhynchus mykiss

\begin{tabular}{|c|c|c|c|c|c|c|c|c|c|}
\hline \multirow[b]{2}{*}{ MANOVA } & \multicolumn{5}{|c|}{ Mare River } & \multicolumn{4}{|c|}{ Pungwe River } \\
\hline & $\mathrm{df}$ & & & $F$ & $P$ & $\mathrm{df}$ & Wilks & $F$ & $P$ \\
\hline $\mathrm{T}$ & 9,8 & & & 9.71 & $<0.001$ & 5,12 & 0.07 & 33.54 & $<0.001$ \\
\hline $\mathrm{T}(\mathrm{P})$ & 18,16 & & & 9.83 & $<0.001$ & 10,24 & 0.03 & 12.56 & $<0.001$ \\
\hline \multicolumn{2}{|l|}{ ANOVA } & df & MS & $F$ & $P$ & $\mathrm{df}$ & MS & $F$ & $P$ \\
\hline \multirow[t]{2}{*}{ Baetis spp. } & $\mathrm{T}$ & 1,16 & 0.50 & 6.14 & 0.02 & 1,16 & 2.26 & 18.51 & $<0.001$ \\
\hline & $\mathrm{T}(\mathrm{P})$ & 2,16 & 3.91 & 48.41 & $<0.001$ & 2,16 & 5.54 & 45.46 & $<0.001$ \\
\hline \multirow[t]{2}{*}{ Pseudoponnata sp. } & $\mathrm{T}$ & 1,16 & 0.21 & 0.61 & 0.45 & & & & \\
\hline & $\mathrm{T}(\mathrm{P})$ & 2,16 & 0.85 & 2.46 & 0.12 & & & & \\
\hline \multirow[t]{2}{*}{ Trichorythidae } & $\mathrm{T}$ & 1,16 & 0.51 & 1.37 & 0.26 & & & & \\
\hline & $\mathrm{T}(\mathrm{P})$ & 2,16 & 1.02 & 2.78 & 0.09 & & & & \\
\hline \multirow[t]{2}{*}{ Hydropsyche sp. 1} & $\mathrm{~T}$ & 1,16 & 1.50 & 6.13 & 0.02 & & & & \\
\hline & $\mathrm{T}(\mathrm{P})$ & 2,16 & 3.02 & 12.36 & $<0.001$ & & & & \\
\hline \multirow[t]{2}{*}{ Cheumatopsyche spp. } & $\mathrm{T}$ & 1,16 & 2.01 & 5.24 & 0.04 & 1,16 & 0.05 & 0.16 & 0.69 \\
\hline & $\mathrm{T}(\mathrm{P})$ & 2,16 & 0.41 & 1.07 & 0.37 & 2,16 & 5.82 & 20.72 & $<0.001$ \\
\hline \multirow[t]{2}{*}{ Afronurus sp. } & $\mathrm{T}$ & 1,16 & 0.34 & 1.31 & 0.27 & 1,16 & 1.60 & 3.50 & 0.08 \\
\hline & $\mathrm{T}(\mathrm{P})$ & 2,16 & 6.65 & 25.42 & $<0.001$ & 2,16 & 4.74 & 10.40 & $<0.001$ \\
\hline \multirow[t]{2}{*}{ Caenis sp. } & $\mathrm{T}$ & 1,16 & 0.01 & 0.08 & 0.78 & 1,16 & 4.07 & 28.07 & $<0.001$ \\
\hline & $\mathrm{T}(\mathrm{P})$ & 2,16 & 1.20 & 7.33 & 0.01 & 2,16 & 4.85 & 33.45 & $<0.001$ \\
\hline \multirow[t]{2}{*}{ Euthralus sp. } & $\mathrm{T}$ & 1,16 & 0.15 & 1.97 & 0.18 & 1,16 & 2.74 & 7.45 & 0.01 \\
\hline & $\mathrm{T}(\mathrm{P})$ & 2,16 & 1.54 & 20.50 & $<0.001$ & 2,16 & 4.21 & 11.45 & $<0.001$ \\
\hline \multirow[t]{2}{*}{ Limnophila sp. } & $\mathrm{T}$ & 1,16 & 1.74 & 6.36 & 0.02 & & & & \\
\hline & $\mathrm{T}(\mathrm{P})$ & 2,16 & 1.00 & 3.67 & 0.05 & & & & \\
\hline
\end{tabular}

The design indicates treatments $(\mathrm{T})$ and sampling period nested within treatments $(\mathrm{T}(\mathrm{P}))$

to the presence of trout as the dominant predator since both the mountain catfish and large predatory macroinvertebrates were generally low in abundance. Many studies have shown that epibenthic, drift-prone grazers such as Baetis spp. often face high predation risk from predators such as trout (Diehl et al., 2000; De Crespin De Billy and Usseglio-Polatera 2002). Often, macroinvertebrates within invaded habitats tend to exhibit predator avoidance behaviour that is shown by their low densities in patches where predation is likely to be high (Englund et al., 2001). The influx of macroinvertebrates into the exclosure treatment that was observed within the trout-invaded reaches suggests an adaptive response that may reflect short-term changes due to predation and behaviour of individual taxa. Overall, the observed patterns suggest that although the mountain catfish is considered to be a top predator, it had less impact on macro-invertebrate density and composition compared to rainbow trout. Introduced predators such as trout have been found to have both direct impact through predation and indirect impact by influencing the responses and behaviours of native biota (Simon \& Townsend, 2003).

\section{Conclusion}

This study has revealed that the mountain catfish occurred at wide depth ranges in uninvaded stream reaches. The presence of rainbow trout, however, was associated with use of shallow habitats and a significant reduction in abundances for the mountain catfish where both species co-occurred. These shallow marginal habitats are most likely to be less ideal for sustenance of large mountain catfish populations and would further expose the mountain catfish to terrestrial predators such as otters and predatory birds. The high abundance of most macro-invertebrates in exclosure 
compared to open treatments within trout-invaded reaches suggests an influence of trout on macroinvertebrate community. This influence may be related to both predation and altered behaviours of different macro-invertebrate taxa. The observed patterns for both the mountain catfish and macro-invertebrates in response to the presence of non-native rainbow trout may have ecological implications such as trophic cascades and predator-prey relationships.

Acknowledgments This study was funded by the British Ecological Society (BES) Overseas Bursary for WTK (Grant No. 2222/2758). Permission to conduct this study within Nyanga National Park was granted by the Zimbabwe Parks and Wildlife Management Authority. TREP (University of Zimbabwe) provided technical support during this study. We thank Ferdy De Moor and Helen Barber-James, at Albany Museum, Grahamstown, for their assistance with macroinvertebrate identification. Brian Marshall provided valuable comments to the previous draft of this manuscript.

Open Access This article is distributed under the terms of the Creative Commons Attribution License which permits any use, distribution, and reproduction in any medium, provided the original author(s) and the source are credited.

\section{References}

Ault, T. R. \& R. W. G. White, 1994. Effects of habitat structure and the presence of brown trout on the population density of Galaxias truttaceus in Tasmania, Australia. Transactions of the American Fisheries Society 123: 939-949.

Barber-James, H. M. \& C. R. Lugo-Ortiz, 2003. Ephemeroptera. In de Moore I. J., J. A. Day \& F. C. de Moore (eds), Guides to the Freshwater Invertebrates of Southern Africa, Vol. 7: Insecta I: WRC report No TT 207/03. DWAF, Pretoria South Africa. 16-159 pp.

Baxter, C. V., K. D. Fausch, M. Murakami \& P. L. Chapman, 2004. Fish invasion restructures stream and forest food webs by interrupting reciprocal prey subsidies. Ecology 85 : 2656-2663.

Bell-Cross, G. \& J. L. Minshull, 1988. The fishes of Zimbabwe. National Museums and Monuments of Zimbabwe, Harare. $291 \mathrm{pp}$.

Bere T., C. Phiri, W. T. Kadye \& B. Utete, 2013. Benthic diatom assemblages in mountain streams: community structure in relation to environmental and human pressures. African Journal of Ecology. doi:10.1111/aje.12078.

Biggs, B. J. F., S. N. Francoeur, A. D. Huryn, R. Young, C. J. Arbuckle \& C. R. Townsend, 2000. Trophic cascades in streams: effects of nutrient enrichment on autotrophic and consumer benthic communities under two different fish predation regimes. Canadian Journal of Fisheries and Aquatic Sciences 57: 1380-1394.
Bonnett, M. L. \& A. R. McIntosh, 2004. The influence of juvenile brown trout (Salmo trutta) on habitat use of inanga (Galaxias maculatus) in a stream simulator. Journal of the Royal Society of New Zealand 34: 357-367.

Bosch, J., P. A. Rincon, L. Boyero \& I. Martinez-Salamo, 2006. Effects of introduced salmonids on a montane population of Iberian frogs. Conservation Biology 20: 180-189.

Butler, J. R. A. \& B. E. Marshall, 1996. Resource use within the crab-eating guild of the Upper Kairezi River, Zimbabwe. Journal of Tropical Ecology 12: 475-490.

Cambray, J. A., 2003. Impact on indigenous species biodiversity caused by the globalisation of alien recreational freshwater fisheries. Hydrobiologia 500: 217-230.

Chakona, A., B. Marshall \& L. Brendonck, 2007. The effect of fish predation on benthic macro-invertebrates in a seasonal stream in north-western Zimbabwe. African Journal of Aquatic Science 32: 251-257.

Chakona, A., C. Phiri, C. H. D. Magadza \& L. Brendonck, 2008. The influence of habitat structure and flow permanence on macro-invertebrate assemblages in temporary rivers in northwestern Zimbabwe. Hydrobiologia 607: 199-209.

Crawford, S. S. \& A. M. Muir, 2008. Global introductions of salmon and trout in the genus Oncorhynchus: 1870-2007. Reviews in Fish Biology and Fisheries 18: 313-344.

De Crespin De Billy, V. \& P. Usseglio-Polatera, 2002. Traits of brown trout prey in relation to habitat characteristics and benthic communities. Journal of Fish Biology 60: $687-714$.

de Moore, F. C., 2002. Simuliidae. In Day J. A., A. D. Harrison \& I. J. de Moore (eds), Guides to the Freshwater Invertebrates of Southern Africa, Vol. 9: Diptera. WRC report No TT 201/02, DWAF, Pretoria South Africa: 75-109 pp.

de Moore, F. C. \& K. M. F. Scott, 2003. Trichoptera. In de Moore I. J., J. A. Day \& F. C. de Moore (eds), Guides to the Freshwater Invertebrates of Southern Africa. Vol. 8: Insecta II. WRC report No TT 214/03, DWAF, Pretoria South Africa, 84-183 pp.

Diehl, S., S. D. Cooper, K. W. Kratz, R. M. Nisbet, S. K. Roll, S. W. Wiseman \& T. M. Jenkins, 2000. Effects of multiple, predator-induced behaviors on short-term producer-grazer dynamics in open systems. American Naturalist 156: 293-313.

Donald, D. B. \& S. R. Anderson, 2003. Resistance of the preyto-predator ratio to environmental gradients and to biomanipulations. Ecology 84: 2387-2394.

Dunham, J. B., S. B. Adams, R. E. Schroeter \& D. C. Novinger, 2002. Alien invasions in aquatic ecosystems: toward an understanding of brook trout invasions and potential impacts on inland cutthroat trout in western North America. Reviews in Fish Biology and Fisheries 12: 373-391.

Englund, R. A. \& D. A. Polhemus, 2001. Evaluating the effects of introduced rainbow trout (Oncorhynchus mykiss) on native stream insects on Kauai Island, Hawaii. Journal of Insect Conservation 5: 265-281.

Englund, G., S. D. Cooper \& O. Sarnelle, 2001. Application of a model of scale dependence to quantify scale domains in open predation experiments. Oikos 92: 501-514.

Fincke, O. M., S. P. Yanoviak \& R. D. Hanschu, 1997. Predation by odonates depresses mosquito abundance in water-filled tree holes in Panama. Oecologia 112: 244-253. 
Flecker, A. S. \& C. R. Townsend, 1994. Community-wide consequences of trout introduction in New Zealand streams. Ecological Applications 4: 798-807.

Fouche, P. S. O., S. H. Foord, N. Potgieter, B. C. W. van der Waal \& T. van Ree, 2005. Towards an understanding of factors affecting the biotic integrity of rivers in the Limpopo Province: niche partitioning, habitat preference and microbiological status in rheophilic biotopes of the Luvuvhu and Mutale Rivers. Water Research Commission Report Number 1197(1/05): 61-132.

Glova, G. J., 2003. A test for interaction between brown trout (Salmo trutta) and inanga (Galaxias maculatus) in an artificial stream. Ecology of Freshwater Fish 12: 247-253.

Glova, G. J., P. M. Sagar \& I. Näslund, 1992. Interaction for food and space between populations of Galaxias vulgaris Stokell and juvenile Salmo trutta L. in a New Zealand stream. Journal of Fish Biology 41: 909-925.

Gorman, O. T. \& J. R. Karr, 1978. Habitat structure and stream fish communities. Ecology 74: 1856-1870.

Harrison, A. D., 2002. Chironomidae. In Day J. A., A. D. Harrison \& I. J. de Moore (eds), Guides to the Freshwater Invertebrates of Southern Africa, Vol. 9: Diptera. WRC report No TT 201/02, DWAF, Pretoria South Africa: 110-158 pp.

Heiberger, R. M. \& B. Holland, 2004. Statistical analysis and data display: an intermediate course with examples in S-Plus, R, and SAS Springer texts in statistics. Springer, New York.

Johnson, P. T. J., J. D. Olden, C. T. Solomon \& M. J. Vander Zanden, 2009. Interactions among invaders: community and ecosystem effects of multiple invasive species in an experimental aquatic system. Oecologia 159: 161-170.

Kadye, W. T. \& A. J. Booth, 2012. Detecting impacts of invasive non-native sharptooth catfish, Clarias gariepinus, within invaded and non-invaded rivers. Biodiversity and Conservation 21: 1997-2015.

Kadye, W. T. \& C. H. D. Magadza, 2008. Trout induces a shift from preferred habitat types for indigenous species: the example of the indigenous catfish, Amphilius uranoscopus (Pfeffer, 1889), on an African montane plateau. Hydrobiologia 614: 329-337.

Kadye, W. T. \& B. Marshall, 2007. Habitat diversity and fish assemblages in an African River basin (Nyagui River, Zimbabwe. African Journal of Ecology 45: 374-381.

Kadye, W. T., N. A. G. Moyo, C. H. D. Magadza \& S. Kativu, 2008. Habitat associations of three stream fishes on a montane plateau (Nyika Plateau, Malawi). Acta Zoologica Sinica 54: 67-76.

Leprieur, F., O. Beauchard, S. Blanchet, T. Oberdorff \& S. Brosse, 2008. Fish invasions in the world's river systems: when natural processes are blurred by human activities. PLoS Biology 6: e26.

MacGown, A. R., 1970. Trout management in a small Rhodesian Highveld impoundment. Rhodesia Science News 4: $57-58$.

Marriott, M. S., A. J. Booth \& P. H. Skelton, 1997. Reproductive and feeding biology of the Natal mountain catfish, Amphilius natalensis (Siluriformes: Amphiliidae). Environmental Biology of Fishes 49: 461-470.

Marshall, B., 2011. The fishes of Zimbabwe and their biology. Smithiana Monograph 3. South African Institute for Aquatic Biodiversity, Grahamstown.
McDowall, R. M., 2003. Impacts of introduced salmonids on native galaxiids in New Zealand upland streams: a new look at an old problem. Transactions of the American Fisheries Society 132: 229-238.

McIntosh, A. R., 2000. Habitat- and size-related variations in exotic trout impacts on native galaxiid fishes in New Zealand streams. Canadian Journal of Fisheries and Aquatic Science 57: 2140-2151.

Meissner, K. \& T. Muotka, 2006. The role of trout in stream food webs: integrating evidence from field surveys and experiments. Journal of Animal Ecology 75: 421-433.

Miller, S. A. \& T. A. Crowl, 2006. Effects of common carp (Cyprinus carpio) on macrophytes and invertebrate communities in a shallow lake. Freshwater Biology 51: 85-94.

Morita, K., J. Tsuboi \& H. Matsuda, 2004. The impact of exotic trout on native charr in Japanese streams. Journal of Applied Ecology 41: 962-972.

Ngugi, C., J. O. Manyala, M. Njiru \& C. M. Mlewa, 2009. Some aspects of the biology of the stargazer mountain catfish, Amphilius uranoscopus (Pfeffer); (Siluriformes: Amphiliidae) indigenous to Kenya streams. African Journal of Ecology 47: 606-613.

Nyström, P. \& A. R. McIntosh, 2003. Are impacts of an exotic predator on a stream food web influenced by disturbance history? Oecologia 136: 279-288.

Nyström, P., O. Svensson, B. Lardner, C. Brönmark \& W. Granéli, 2001. The influence of multiple introduced predators on a littoral pond community. Ecology 82: 1023-1039.

Parker, I. M., D. Simberloff, W. M. Lonsdale, K. Goodell, M. Wonham, P. M. Kareiva, M. H. Williamson, B. Von Holle, P. B. Moyle, J. E. Byers \& L. Goldwasser, 1999. Impact: toward a framework for understanding the ecological effects of invaders. Biological Invasions 1: 3-19.

Penaluna, B. E., I. Arismendi \& D. Soto, 2009. Evidence of interactive segregation between introduced trout and native fishes in northern Patagonian Rivers, Chile. Transactions of the American Fisheries Society 138: 839-845.

Pimentel, D., 2011. Biological invasions: economic and environmental costs of alien plant, animal and microbe species, 2nd ed. CRC Press, Boca Raton, FL: 449.

Power, M. E., 1984. Depth distributions of armoured catfish: predator-induced resource avoidance? Ecology 65: 523-528.

Quinn, G. \& M. Keough, 2002. Experimental design and data analysis for biologists. Cambridge University Press, Cambridge, UK.

R Development Core Team, 2012. R: A Language and Environment for Statistical Computing. R Foundation for Statistical Computing, Vienna.

Rahel, F. J., 2002. Homogenization of freshwater faunas. Annual Review of Ecology and Systematics 33: 291-315.

Samways, M. J. \& B. Wilmot, 2003. Odonata. In de Moor, I. J., J. A. Day, F. C. de Moor (eds), Guides to the Freshwater Invertebrates of southern Africa, Vol. 7: Insecta, 1 Ephemeroptera, Odonata and Plecoptera. pp. 160-212. Water Research Commission, Gezina.

Schlosser, I. J., 1982. Fish community structure and function along two habitat gradients in headwater stream. Ecological Monographs 52: 395-414.

Schofield, K., C. R. Townsend \& A. G. Hildrew, 1988. Predation and the prey community of a headwater stream. Freshwater Biology 20: 85-95. 
Simon, K. S. \& C. R. Townsend, 2003. Impacts of freshwater invaders at different levels of ecological organization, with emphasis on salmonids and ecosystems consequences. Freshwater Biology 48: 982-994.

Strauss, S. Y., J. A. Lau \& S. P. Carroll, 2006. Evolutionary responses of natives to introduced species: what do introductions tell us about natural communities? Ecology Letters 9: 357-374.

Strayer, D. L., 2010. Alien species in fresh waters: ecological effects, interactions with other stressors, and prospects for the future. Freshwater Biology 55: 152-174.

Swartz, E. R., A. F. Flemming \& F. N. P. le Mouton, 2004. Contrasting genetic patterns and population histories in three threatened redfin species (Cyprinidae) from the Olifants River System, western South Africa. Journal of Fish Biology 64: 1153-1167.

Toots, H., 1970. Exotic fishes in Rhodesia. Rhodesia Agricultural Journal 67: 83-88.

Townsend, C. R., 1996. Invasion biology and ecological impacts of brown trout (Salmo trutta) in New Zealand. Biological Conservation 78: 13-22.

Townsend, C. R. \& T. A. Crowl, 1991. Fragmented population structure in a native New Zealand fish: an effect of introduced brown trout? Oikos 61: 347-354.
Turnbull-Kemp, P. J., 1957. Trout in Southern Rhodesia. Rhodesia Agricultural Journal 54: 364-370.

Tweddle, D., R. Bills, E. Swartz, W. Coetzer, L. Da Costa, 542 J. Engelbrecht, J. Cambray, B. Marshall, D. Impson, P. H. Skelton, W. R. T. Darwall \& K. S. Smith, 2009. The status and distribution of freshwater fishes. In Darwall, W. R. T., K. G. Smith, D. Tweddle \& P. H. Skelton (eds), The Status and Distribution of Freshwater Biodiversity in Southern Africa, Gland (Switzerland) and Grahamstown (South Africa): IUCN and South African Institute for Aquatic Biodiversity: 21-37 pp.

van Oosterhout, M. P., G. van der Velde \& I. G. Gaigher, 2009. High altitude mountain streams as possible refuge habitat for mountain catfish, Amphilius uranoscopus. Environmental Biology of Fishes 84: 109-120.

Welcomme, R. L., 1988. International introductions of inland aquatic species. United Nations Food and Agricultural Organization, Rome, Italy. 318 pp.

Young, K. A., J. B. Dunham, J. F. Stephenson, A. Terreau, A. F. Thailly, G. Gajardo \& C. Garcia de Leaniz, 2010. A trial of two trouts: comparing the impacts of rainbow and brown trout on a native galaxiid. Animal Conservation 13: 399-410. 